\title{
Assortative Mating on Ideology Could Operate Through Olfactory Cues
}

\section{Citation}

McDermott, Rose, Dustin Tingley, and Peter K. Hatemi. 2014. "Assortative Mating on Ideology Could Operate Through Olfactory Cues." American Journal of Political Science 58 (4): 997-1005. https://doi.org/10.1111/ajps.12133.

\section{Permanent link}

http://nrs.harvard.edu/urn-3:HUL.InstRepos:38057799

\section{Terms of Use}

This article was downloaded from Harvard University's DASH repository, and is made available under the terms and conditions applicable to Other Posted Material, as set forth at http:// nrs.harvard.edu/urn-3:HUL.InstRepos:dash.current.terms-of-use\#LAA

\section{Share Your Story}

The Harvard community has made this article openly available.

Please share how this access benefits you. Submit a story. 


\title{
Assortative Mating on Ideology Could Operate Through Olfactory Cues
}

\author{
Rose McDermott Brown University \\ Dustin Tingley Harvard University \\ Peter K. Hatemi Pennsylvania State University
}

\begin{abstract}
Mates appear to assort on political attitudes more than any other social, behavioral, or physical trait, besides religion. Yet the process by which ideologically similar mates end up together remains ambiguous. Mates do not appear to consciously select one another based on ideology, nor does similarity result from convergence. Recently, several lines of inquiry have converged on the finding that olfactory processes have an important role in both political ideology and mate selection. Here we integrate extant studies of attraction, ideology, and olfaction and explore the possibility that assortation on political attitudes may result, in part, from greater attraction to the scent of those with shared ideology. We conduct a study in which individuals evaluated the body odor of unknown others, observing that individuals are more attracted to their ideological concomitants.
\end{abstract}

imilarity between spouses is common across domains, but in humans, long-term mates correlate more highly (between 0.60 and 0.75 ) on social and political attitudes than almost any other trait, with the exception of religion (Alford et al. 2011; Byrne 1961; Cavior, Miller, and Cohen 1975; Curry and Kenny 1974; Eaves et al. 1999; Eaves and Hatemi 2011; Feng and Baker 1994; Hatemi et al. 2010; Martin et al. 1986; Stoker and Jennings 1995, 2006; Zietsch et al. 2011; Zuckerman, Fitzgerald, and Dasovic 2005). The processes that result in religious assortation are well understood, resulting largely from social homogamy and proximity effects (e.g., Eaves, Martin, and Heath 1990; Kalmijn 1998). However, we know much less about the mechanisms that produce high levels of spousal correlation on left-right political dimensions. Unlike religion, assortative mating on attitudes does not appear to result from partners becoming more similar over time, social homogamy, or direct selection (Alford et al. 2011; Klofstad, McDermott, and Hatemi 2012, 2013; Kofoed 2008; Rantala and Marcinkowska 2011).

The findings that attitudes are not only socially driven, but are equally informed by genetic and neurobiological mechanisms may provide valuable insight into understanding some of the foundations of assortative mating on the basis of political ideology. A growing body of evidence reveals that the mechanisms that account for differences in ideological attitudes are genetically and biologically influenced and conscript olfactory processes (Chapman et al. 2009; Chapuisat 2009; Fowler and Christakis 2013; Fowler and Schreiber 2008; Haidt 2012; Hatemi et al. 2011; Hatemi et al. 2014; Herz and Inzlicht 2002; Inbar et al. 2012; Inbar, Pizarro, and Bloom 2012; Navarrete and Fessler 2006). In this research note, we integrate these lines of inquiry and reveal that people find the smell of ideologically similar others more attractive, thereby providing preliminary evidence suggesting that one of the mechanisms by which political assortative mating occurs is through subconscious sexual attraction to variant body odors.

\section{Olfaction and Mate Selection}

Olfactory mechanisms have proven important in mate seeking and reproduction in both humans and animals

Rose McDermott is Full Professor of Political Science, Brown University, 36 Prospect St., Providence, RI 02906 (rmcdermott21@gmail.com). Dustin Tingley is Paul Sack Associate Professor of Political Economy, Government Department, Harvard University, 1737 Cambridge St., K208, Cambridge, MA 02138 (dtingley@gov.harvard.edu). Peter K. Hatemi is Associate Professor of Political Science, Microbiology, and Biochemistry, Pennsylvania State University, 307 Pond Lab, University Park, PA 16802 (phatemi@gmail.com).

We thank Kelly Gildersleeve and the Martie Haselton Lab at UCLA for their scent protocol and guidance. Replication data for this article are available in the AJPS Data Archive on Dataverse (http://thedata.harvard.edu/dvn/dv/ajps).

American Journal of Political Science, Vol. 00, No. 00, May 2014, Pp. 1-9

(C) 2014, Midwest Political Science Association

DOI: 10.1111/ajps.12133 
because smell may signal mate immunocompetence, social compatibility, or other characteristics associated with mate quality and optimal reproduction (Blaustein 1981; Brennan 2004; Folstad and Karter 1992; Milinski and Wedekind 2001; Miller, Tybur, and Jordan 2007; Penn and Potts 1998; Thornhill and Gangestad 1999). While most senses operate through the brain stem and thalamus, the olfactory bulb has direct connections with the seat of emotion in the amygdala and the center of memory in the hippocampus. This indicates the importance that natural selection placed on odorants, in some ways privileging speed of learning by smell over that offered by vision or hearing. For example, Herz and Inzlicht (2002) found that women ranked body odor as more important for attraction than any other physical factor, including looks; only the social factor of "pleasantness" emerged more dominant in evaluations. Moreover, liking someone's natural body odor was the most influential olfactory variable driving sexual interest for both men and women.

The most prominent explanation for how attraction operates through olfactory and chemosensory channels has relied on the finding that individuals tend to be more attracted to the odor of those whose major histocompatibility complex (MHC) offers optimal complementarity to one's own (Brennan 2004; Thornhill et al. 2003; Wedekind and Furi 1997). MHC variants have a significant role in immune, odor, and kin recognition; susceptibility to diseases; mate selection; and pregnancy outcomes. Indeed, many scholars propose that the loss of MHC variation negatively affects population survival (Radwan, Biedrzycka, and Babik 2010). Milinski et al. (2013) find that humans have the ability to detect and evaluate MHC peptides in body odor, and this ability is mediated by genotype, which may provide a basis for the sensory evaluation of potential partners during human mate choice (Davis 2013; Woelfing et al. 2009). ${ }^{1}$ In this way, optimal complementarity in MHC may include some combination of different and shared MHC alleles (Nowak, TarczyHornoch, and Austyn 1992).

MHC, however, constitutes only one mechanism by which olfactory processes influence sexual selection (Havlicek and Roberts 2009). Indeed, numerous other mechanisms have been proposed to explain why individuals find those with particular scents more attractive, including processes of imprinting, defined as acquisition of sexual preferences that emerge through unrewarded experiences with parents beginning in utero, and contin-

\footnotetext{
${ }^{1}$ There remains some debate as to whether MHC retains as substantial a role in social behavior (reviewed in Penn and Potts 1999). For example, much of the evidence that supports MHC's influence on sexual selection operating through heterozygous attraction is based on inbred groups of mice.
}

uing through early development (Bereczkei, Gyuris, and Weisfeld 2004; Rikowski and Grammer 1999; Thornhill and Gangestad 1999), and pathogen avoidance (Faulkner et al. 2004; Navarrete and Fessler 2006). We discuss these processes in more detail below.

\section{Olfaction and Political Ideology}

Why and how might smell signals be linked to political ideology? Smell signals help maximize prospects for disease avoidance, cheater detection, defense against outgroups, and social cohesion (Chapuisat 2009; Fowler and Christakis 2013). These topics are embedded within attitudinal measures of ideology. For example, greater disgust sensitivity, which is intimately interconnected with the neural substrates of smell, predicts more conservative positions, particularly around issues involving morality and sexual reproduction. These underlying, physically experienced predilections can come to be expressed as opinions on such topics as abortion, homosexuality, gay marriage, and a host of other ideological topics (Heining et al. 2003; Inbar et al. 2012; Inbar, Pizarro, and Bloom 2012; Phillips et al. 1997). In a related vein, Navarrete and Fessler (2006) find that ethnocentrism represents an evolved function designed to avoid disease and to protect individuals from dissimilar others. These attitudes manifest in left-right political orientations (for earlier developments, see Faulkner et al. 2004; Folstad and Karter 1992).

\section{Olfaction, Mating, and Political Ideology}

Olfaction correlates in specific ways with differing political preferences through genetic and biological mechanisms similar to those employed in choice of sexual partners. As noted above, spouses and long-term partners appear to be more similar in their political preferences than almost any other trait. This affinity exists prior to marriage, and the length of marriage appears to have little effect on spousal similarity in ideology (Alford et al. 2011; Caspi and Herbener 1993; Feng and Baker 1994; Kofoed 2008; Watson et al. 2004). Suggestively, Hatemi et al. (2011) identified several genomic regions that account for variation in ideological orientation, one of which contained a large number of olfactory receptors. They proposed that "if olfactory receptors account for some variation on political preferences, they may do so 
through intended optimal breeding and rearing strategies such as spousal selection" (Hatemi et al. 2011, 280). Davis (2013), in a thorough examination of genetics and mate selection, provides evidence that genotype influences how attractive a person is to a potential partner because suitable mates display differential smell preference for partners with an optimal genetic code for them. In this way, people may be subconsciously choosing an optimal mating partner who would increase the probability of having children with more social and genetic advantages.

These dynamics may represent an extension of imprinting whereby offspring "fashion a mental model of their opposite-sex parent's phenotype that is used as a template for acquiring mates" (Bereczkei, Gyuris, and Weisfeld 2004, 1129). For example, fetuses come to prefer scents that most populate their mother's world (Browne 2008), and humans, including mothers, spend most of their time around ideologically similar others (e.g., Fowler, Settle, and Christakis 2011; Posner et al. 1996). If social attitudes are linked to odor, as the literature suggests, then one mechanism that odor preferences transfer from parents to children may operate through their mother's choice of mate. In this way, social processes may drive some of the pathways by which individuals come to prefer those whose ideological "smell" matches their own (e.g., Schaal, Marlier, and Soussignan 2000).

Political compatibility may also serve as a modern representation of a host of mechanisms and values that directly affect physiological and sexual compatibility as well as child-rearing strategies. This is because parental similarity in values increases the likelihood that such individuals may be able to stay together long enough to raise their children successfully into adulthood in order to potentiate their own reproductive success. Uniform parental rearing practices also provide consistently better outcomes for child learning and development than conflicting value structures (Block, Block, and Morrison 1981). In addition, parents who share particular political values, and thus get along better, may find it easier to elicit social support and social capital than those constantly prone to infighting. Such social support increases health and longevity (Cacioppo and Hawkley 2003; Hawkley et al. 2003; Hawkley and Cacioppo 2003).

In summary, olfactory signals communicate important characteristics of mate quality, providing an efficient evolutionary mechanism by which to enhance reproduction. In this way, attraction to the smell of those with similar attitudes may reflect the ontological remnants of a more primitive behavioral adaptation designed to ensure reproductive success. We propose that modern assortation on political attitudes may rest, in part, on an evolved system that is designed to optimize prospects for successful reproduction by selecting partners who closely align on parental investment strategies and other critical values regarding sex and reproduction. Just as adult individuals prefer smells that populate their mother's world in utero and their world in childhood (Browne 2008; Mennella, Jagnow, and Beauchamp 2001), we suggest that mates find those who are homogamous on social and political ideologies more attractive, and propose that this preference helps maximize prospects for successful and enduring mating, interpersonal bonding, and compatible parenting strategies.

\section{Materials and Methods}

We conducted a study where participants rated the attractiveness of the body odor of unknown strong liberals and strong conservatives, hereafter referred to as "target" subjects; all "evaluator" subjects remained blind to the ideology of the target samples. One hundred forty-six participants between $18-40$ years old were drawn from a large city in the northeast United States; half were drawn from a volunteer subject pool associated with a large university, and the other half were taken from the general population solicited through media advertisements, electronic mailing lists, and other forms of social networks. Informed consent was obtained from all participants. Twenty-one target participants were selected for their high scores on opposite ends of the political spectrum (10 liberals and 11 conservatives) and provided body odor samples, in accordance with established protocols for sample collection and storage (Haselton and Gildersleeve 2011). Eleven of these target participants were female and 10 were male (see the online supporting information for cross-tabulations and additional descriptive information, including instructions given to participants). Ideology was measured using the standard 7-point (strongly liberal to strongly conservative) American National Election Studies (ANES) self-report measure: "Here is a 7-point scale on which the political views that people might hold are arranged from extremely liberal to extremely conservative. Where would you place yourself on this scale?" (ANES 2012). Target participants washed in fragrancefree shampoo and soap and then taped one $2 \times 2$ Johnson $\&$ Johnson gauze pad to each underarm using Johnson \& Johnson paper tape, all of which we provided. Participants wore these pads for 24 hours following a strict protocol that prohibited smoking, drinking, deodorants, perfumes, being around strong odors or candles, animals, eating strong-smelling foods, having sex, or sleeping in a 


\section{Figure 1 Sample Population Ideology and Sex}
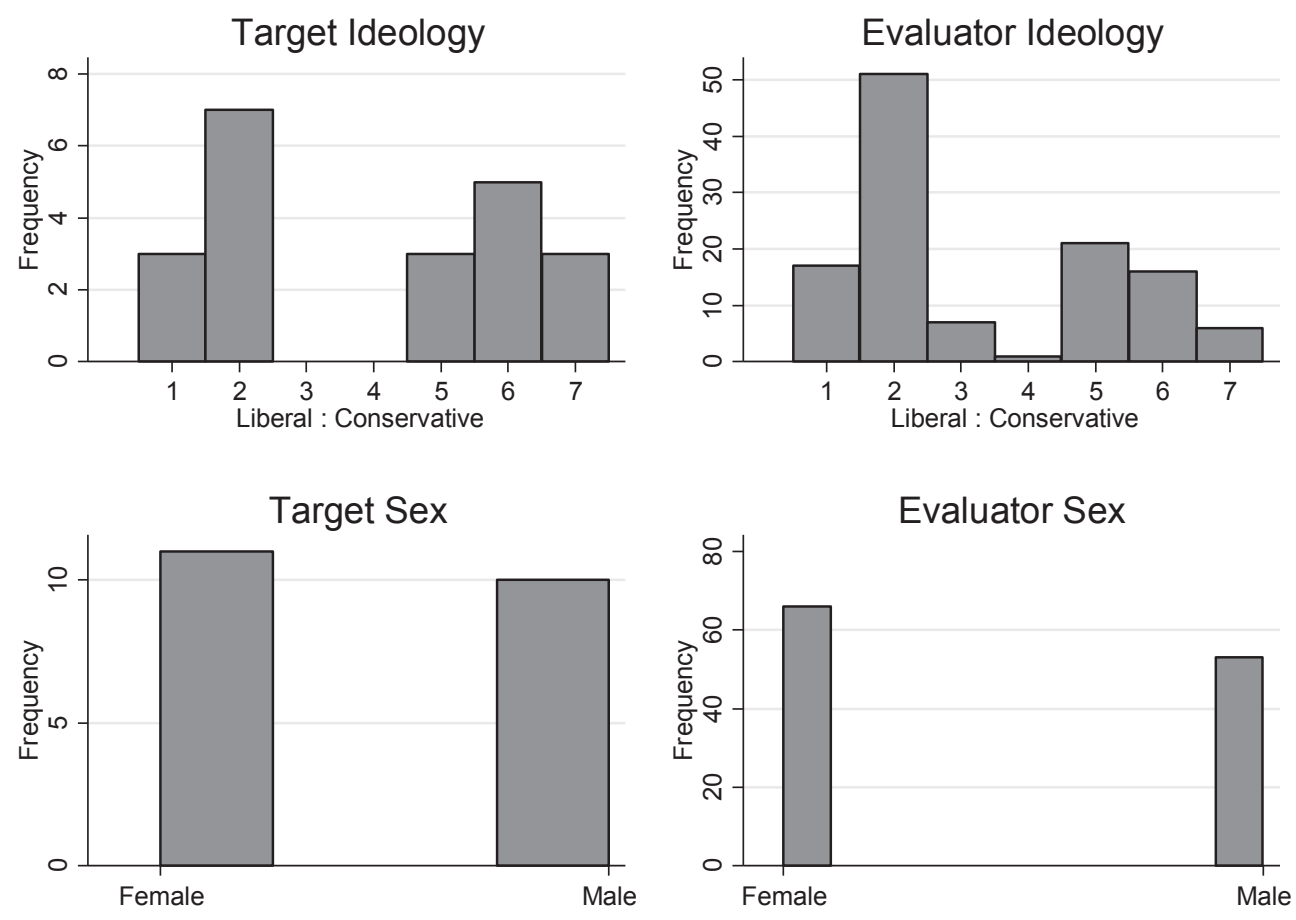

Note: The sexual categories are binary, and the ideological ones exist on a 7-point scale ranging from very liberal (1) to very conservative (7).

bed with any other people or pets. Smokers, those who reported more than four drinks a day, and menstruating or pregnant women were excluded from the study. Compliance was ascertained when participants returned their samples to the lab 24 hours later. One sample was excluded because the participant wore the pads too long, returning them the day after they were requested, making this sample not commensurate with the others. Samples were transferred into sterile containers and frozen at -32 degrees Celsius in a secure freezer in the laboratory. A week later, 125 participants evaluated the body odor of each of the target participants by smelling each vial containing a target participant's gauze pads. Samples were thawed one hour prior to use and used for two hours subsequent to thaw. Each subject smelled each vial individually in randomized order; vials were identified by number. Subject fatigue was minimized by having subjects smell small pieces of paper dipped in peppermint essential oil between each sample to refresh the nasal canal, in keeping with previous protocol in this area (Haselton and Gildersleeve 2011). Each subject rated the attractiveness of each vial on a 5-point Likert scale ranging from least to most attractive. In addition, each subject was asked to guess the political ideology of each sample on the ANES left-right 7point continuum. Upon inquiry, no participant claimed to recognize any target body odor. Figure 1 provides the descriptives of our evaluator subject sample. The sample is slightly more female and liberal, although we made every effort to recruit equal numbers by sex and across the political spectrum, including contacting every Republican club at five universities in the greater metropolitan area and asking the conservative subjects we ascertained to contact any of their ideological compatriots and encourage them to participate in the study.

\section{Analyses and Results}

We estimated interpersonal attraction for odor as a function of both targets' and evaluators' ideologies and sex. We use ordinary least squares with robust standard errors clustered at the evaluator level. The dependent variable is the reported level of attraction. Subtracting the target's average attractiveness and using this transformed variable as a dependent variable produces similar results. We estimate several different models (see Table 1).

Model 1 uses binary versions of our ideology variables, classifying anyone with an ideology score of 4 and up as conservative. As explanatory variables, we use an 


\section{TABLE 1 Odor Attraction as a Function of Ideological Similarity}

\begin{tabular}{|c|c|c|c|}
\hline & Model 1 & Model 2 & Model 3 \\
\hline Same Ideology & $\begin{array}{c}0.0853 \\
(0.0504)\end{array}$ & & \\
\hline -Abs. Ideology Diff. & & $\begin{array}{c}0.0206 \\
(0.0139)\end{array}$ & $\begin{array}{c}0.0226 \\
(0.0156)\end{array}$ \\
\hline Same Sex & $\begin{array}{c}-0.144 \\
(0.0430)\end{array}$ & $\begin{array}{l}-0.143 \\
(0.0431)\end{array}$ & $\begin{array}{c}-0.143 \\
(0.0443)\end{array}$ \\
\hline Conservative Eval. & $\begin{array}{r}-0.00557 \\
(0.00428)\end{array}$ & & \\
\hline Conservative Target & $\begin{array}{c}0.0196 \\
(0.0513)\end{array}$ & & \\
\hline Ideology of Eval. & & $\begin{array}{r}-0.000919 \\
(0.00101)\end{array}$ & \\
\hline Ideology of Target & & $\begin{array}{r}0.00561 \\
(0.0120)\end{array}$ & \\
\hline Male Evaluator & $\begin{array}{c}-0.0000277 \\
(0.00412)\end{array}$ & $\begin{array}{r}0.000401 \\
(0.00417)\end{array}$ & \\
\hline Male Target & $\begin{array}{c}-0.0174 \\
(0.0439)\end{array}$ & $\begin{array}{c}-0.0141 \\
(0.0464)\end{array}$ & \\
\hline Avg. Target Attract & $\begin{array}{c}0.999 \\
(0.0655)\end{array}$ & $\begin{array}{l}1.001 \\
(0.0654)\end{array}$ & \\
\hline Avg. Eval. Attract & $\begin{array}{l}0.999 \\
(0.00339)\end{array}$ & $\begin{array}{l}0.999 \\
(0.00367)\end{array}$ & \\
\hline Constant & $\begin{array}{r}-3.576 \\
(0.231)\end{array}$ & $\begin{array}{r}-3.506 \\
(0.233)\end{array}$ & $\begin{array}{c}3.290 \\
(0.142)\end{array}$ \\
\hline Observations & 2195 & 2195 & 2195 \\
\hline
\end{tabular}

Note: Standard errors are clustered at evaluator level in parentheses.

indicator for whether the evaluator is conservative (Conservative Eval.), whether the target is conservative (Conservative Target), and whether the target and evaluator have the same ideology (Same Ideology). We also control for sex, using indicators for whether the evaluator is a male (Male Evaluator), whether the target is a male (Male Target), and whether the target and evaluator both are the same sex (Same Sex). Finally, we include the average attractiveness of each target (Avg. Target Attract), as well as each evaluator's average reported attraction (Avg. Eval. Attract). ${ }^{2}$ The results in Model 1 show a positive coefficient for targets and evaluators having the same ideology $(t=1.69)$ and a negative coefficient on being the same $\operatorname{sex}(t=-3.34)$, which is consistent with our theoretical expectations.

${ }^{2}$ We are aware that some of these results might be distorted by individual subjects' sexual orientation. However, the institutional review board would not allow us to inquire into subjects' sexual orientation, so we were not able to obtain this information.
Models 2 and 3 use a different estimation strategy. Here we retain the continuous nature of our ideology variable and calculate the absolute value of the difference between the target's and evaluator's ideology, multiplied by negative 1 (-Abs. Ideology Diff.). Larger values indicate greater ideological similarity between the target and evaluator. In Model 2, we control for evaluator (Ideology of Eval.) and target ideology (Ideology of Target; both continuous measures), sex, and average attraction levels. In Model 3, we include evaluator and target fixed effects, and any variables that are constant at the evaluator and target levels are dropped. In both models, we observe the hypothesized positive coefficient on the negative absolute difference in ideology scores (-Abs. Ideology Diff.), though in both cases the coefficient is less precisely estimated $(\mathrm{t}=1.48$ in Model 1 and $\mathrm{t}=1.45$ in Model 2), but still with one-sided p-values less than 0.1 . In all cases, the substantive effect of ideological similarity is small, which is to be expected.

The analyses above support our hypotheses and design based on our assumptions. However, different assumptions and constructions of the relationships between target and evaluator may necessitate using alternative methods. As a result, we conduct additional analyses that others might find beneficial, allowing readers to place our results in different contexts, including the use of jackknife standard errors, mixed models to account for random and fixed effects, and two-way clustering. We discuss the results of these models in the supporting information due to space constraints. Generally, the results are similar to what is presented above.

\section{Discussion}

Several important and unique results emerge from this study. First, individuals find the smell of those who are more ideologically similar to themselves more attractive than those endorsing opposing ideologies; recall that participants never saw the individuals whose smells they were evaluating, and the order of target subjects was randomized for each evaluator. Thus, the recognition of political alignment occurred through the medium of attraction, not recognition.

The amount of variation explained by odor attraction is small, but this should not be surprising and remains consistent with studies on the biological properties of other critical dimensions of social compatibility, including sharing (Nettle et al. 2011), cheater detection (Cosmides et al. 2005), disease avoidance (Neuberg, Kenrick, and Schaller 2011), and sexuality (Miller 2011). 
It is important to recognize that olfactory processes operate within complex social dynamics and environmental contexts. This is particularly true of humans who can override or alter the importance of chemical signals for conscious reasons. In humans, attraction remains idiosyncratic and culturally informed, with greater emphasis placed on physical and sociocultural features (Buss 1987; Jones et al. 1995). Various aspects of attraction indicative of fecundity, such as youth, beauty, hip-to-waist ratio in women (Singh 1993), and the ability to provide resources in men (Townsend and Levy 1990), have historically represented cross-cultural norms, to some degree. Nevertheless, such behaviors do not necessarily obviate the basic "chemistry" that influences how individuals feel toward specific others. We suggest olfaction provides a similar signal of compatibility to potential mates.

Some insight on the potency of odor might be gained from the participants' comments and physical reactions during the study, not adequately captured in the quantitative analyses, but consistent with Herz and Inzlicht (2002). In one particularly illustrative case, a participant asked the experimenter if she could take one of the vials home with her because she thought it was "the best perfume I ever smelled"; the vial was from a male who shared an ideology similar to the evaluator. She was preceded by another respondent with an ideology opposite to the person who provided the exact same sample; this participant reported that that vial had "gone rancid" and suggested it needed to be replaced. In this way, different participants experienced the exact same stimulus in radically different ways only moments apart.

We do not claim that olfactory mechanisms establish an immediate or proximal cause of mate attraction, the strongest predictor of attraction, or represent the only influence on attraction, or that ideology is the only moderator of odor attraction. Indeed, the influence of smell constitutes only one of thousands of potential factors that operate as part of the complex interaction between local ecology, immediate environment, parenting, culture, physiology, and neurobiology. Nor do we understand the exact basis for these differences in olfactory perception; we await future studies that replicate and extend these findings before any definitive relationship is claimed. A number of studies have identified genetic differences in odor sensitivity (Keller et al. 2007), others have focused on pathogen avoidance (Navarrete and Fessler 2006), and others have found some part of smell preferences originate in utero and are heavily influenced by early aspects of development, potentially through imprinting, in the ways suggested above (Mennella, Jagnow, and Beauchamp 2001).
How might this process operate in the real world and in real time, where our environments and backgrounds influence the people we are exposed to and meet, and affect the environments in which we communicate with those we see, hear, and smell? We expect that while humans are generally aware of what they are doing, and often make conscious and cognitive choices to override more basic physical desires, it is most likely that odor operates subtly and may affect the regulation of hormonal states and instigate changes in emotional mood. Such mechanisms do not vitiate the reality or influence of odor on natural or initial attraction. Olfactory cues may provide automatic but indirect indicators that enhance immediate attraction and increase the likelihood that politically similar partners find each other socially and sexually appealing over time (Martins et al. 2005), and thus remain together long enough to improve their mutual prospects for reproductive success (Davis 2013). Conversely, potential mates who might otherwise appear appropriate may not spark any sense of natural "chemistry" with one another because they do not align politically or otherwise. While people can choose to dismiss or ignore these signals in favor of more conscious considerations, it appears nature stacks the deck to make politically similar partners more attractive to each other in unconscious ways, at least over the long haul. Such information may not be useful in all mating contexts, particularly among those seeking short-term partnerships. Nevertheless, long-term mates do align on political ideology more than would be expected by chance, and modern human mating strategies, which clearly rely on overt cues and communication, likely remain informed by evolved mechanisms, such as olfactory cues, to trigger and signal sexual, social, and political compatibility. Individuals are not run by instinct alone, but complex anatomical processes continue to inform cognitive, emotive, and evaluative choices in mating, and ideology has some role in this complex process.

\section{References}

Alford, John R., Peter K. Hatemi, John R. Hibbing, Nicholas G. Martin, and Lindon J. Eaves. 2011. "The Politics of Mate Choice." Journal of Politics 73(2): 362-79.

American National Election Studies. 2012. "American National Election Study, 2008: Pre- and Post-Election Survey." Ann Arbor, MI: Inter-university Consortium for Political and Social Research.

Bereczkei, Tamas, Petra Gyuris, and Glenn E. Weisfeld. 2004. "Sexual Imprinting in Human Mate Choice." Proceedings of the Royal Society of London, Series B: Biological Sciences 271(1544): 1129-34.

Blaustein, Andrew R. 1981. "Sexual Selection and Mammalian Olfaction.” The American Naturalist 117(6): 1006-10. 
Block, Jeanne H., Jack Block, and Andrea Morrison. 1981. "Parental Agreement-Disagreement on Child-Rearing Orientations and Gender-Related Personality-Correlates in Children." Child Development 52(3): 965-74.

Brennan, Peter A. 2004. "The Nose Knows Who's Who: Chemosensory Individuality and Mate Recognition in Mice." Hormones and Behavior 46(3): 231-40.

Browne, Joy V. 2008. "Chemosensory Development in the Fetus and Newborn." Newborn and Infant Nursing Reviews 8(4): 180-86.

Buss, David 1987. "Mate Selection Criteria: An Evolutionary Perspective." In Sociobiology and Psychology: Ideas, Issues and Applications, ed. Charles Crawford, Martin Smith, and Dennis Krebs. Hillsdale, NJ: Lawrence Erlbaum, 335-51.

Byrne, Donn. 1961. "Interpersonal Attraction and Attitude Similarity.” Journal of Abnormal Social Psychology 62(3): 713-15.

Cacioppo, John T., and Louise C. Hawkley. 2003. "Social Isolation and Health, with an Emphasis on Underlying Mechanisms." Perspectives in Biology and Medicine 46(3 Suppl.): S39-S52.

Caspi, Avshalom, and Ellen S. Herbener. 1993. "Marital Assortment and Phenotypic Convergence: Longitudinal Evidence." Biodemography and Social Biology 40(1-2): 48-60.

Cavior, Norman, Karen Miller, and Stanley H. Cohen. 1975. "Physical Attractiveness, Attitude Similarity, and Length of Acquaintance as Contributors to Interpersonal Attraction among Adolescents." Social Behavior and Personality 3(2): 133-42.

Chapman, H. A., D. A. Kim, J. M. Susskind, and A. K. Anderson. 2009. "In Bad Taste: Evidence for the Oral Origins of Moral Disgust." Science 323(5918): 1222-6. http://www. sciencemag.org/content/323/5918/1222

Chapuisat, Michel. 2009. "Social Evolution: The Smell of Cheating.” Current Biology 19(5): R196-R98.

Cosmides, Leda, John Tooby, Laurence Fiddick, and Gregory A. Bryant. 2005. "Detecting Cheaters." Trends in Cognitive Sciences 9(11): 505-506.

Curry, Timothy J., and David A. Kenny. 1974. "The Effects of Perceived and Actual Similarity in Values and Personality in the Process of Interpersonal Attraction." Quality \& Quantity 8(1): 27-44.

Davis, Daniel M. 2013. The Compatibility Gene: How Our Bodies Fight Disease, Attract Others, and Define Our Selves. New York: Oxford University Press.

Eaves, Lindon J., and Peter K. Hatemi. 2011. "Do We Choose Our Spouse Based on Our In-Laws? Resolving the Effects of Family Background and Spousal Choice for Educational Attainment, Religious Practice, and Political Preference." Social Science Quarterly 92(5): 1253-78.

Eaves, Lindon, Andrew Heath, Nicholas Martin, Hermine H. Maes, Michael C. Neale, Kenneth Kendler, Katherine Kirk, and Linda Corey. 1999. "Comparing the Biological and Cultural Inheritance of Personality and Social Attitudes in the Virginia 30,000 Study of Twins and Their Relatives." Twin Research 2(2): 62-80.

Eaves, Lindon, Nicholas Martin, and Andrew Heath. 1990. "Religious Affiliation in Twins and Their Parents: Testing a
Model of Cultural Inheritance." Behavior Genetics 20(1): $1-22$.

Faulkner, Jason, Mark Schaller, Justin H. Park, and Lesley A. Duncan. 2004. "Evolved Disease-Avoidance Mechanisms and Contemporary Xenophobic Attitudes." Group Processes \& Intergroup Relations 7(4): 333-53.

Feng, Du, and Laura Baker. 1994. "Spouse Similarity in Attitudes, Personality, and Psychological Well-Being." Behavior Genetics 24(4): 357-64.

Folstad, Ivar, and Andrew John Karter. 1992. "Parasites, Bright Males, and the Immunocompetence Handicap." The American Naturalist 139(3): 603-22.

Fowler, James H., and Nicholas A. Christakis. 2013. “Friendship and Natural Selection." University of California, San Diego.

Fowler, James H., and Darren Schreiber. 2008. "Biology, Politics, and the Emerging Science of Human Nature." Science 322(5903): 912-14.

Fowler, James H., Jaime E. Settle, and Nicholas A. Christakis. 2011. "Correlated Genotypes in Friendship Networks." Proceedings of the National Academy of Sciences 108(5): 1993-97.

Haidt, Jonathan. 2012. The Righteous Mind: Why Good People Are Divided by Politics and Religion. New York: Vintage Books.

Haselton, Martie G., and Kelly Gildersleeve. 2011. "Can Men Detect Ovulation?" Current Directions in Psychological Science 20(2): 87-92.

Hatemi, Peter K., Nathan A. Gillespie, Lindon J. Eaves, Brion S. Maher, Bradley T. Webb, Andrew C. Heath, Sarah E. Medland, David C. Smyth, Harry N. Beeby, Scott D. Gordon, Grant W. Montgomery, Ghu Zhu, Enda M. Byrne, and Nicholas G. Martin. 2011. "A Genome-Wide Analysis of Liberal and Conservative Political Attitudes.” Journal of Politics 73(1): 271-85.

Hatemi, Peter K., John R. Hibbing, Sarah E. Medland, Matthew C. Keller, John R. Alford, Kevin B. Smith, Nicholas G. Martin, and Lindon J. Eaves. 2010. "Not by Twins Alone: Using the Extended Family Design to Investigate Genetic Influence on Political Beliefs." American Journal of Politcal Science 54(3): 798-814.

Hatemi, Peter K., Sarah E. Medland, R. Klemmensen, S. Oskarsson, Levente Littvay, C. Dawes, B. Verhulst, Rose I. McDermott, A. Sonne Nørgaard, C. A. Klofstad, K. Christenen, Lindon J. Eaves, and Nicholos Martin. 2014. "Genetic Influences on Political Ideologies: Twin Analyses of 19 Measures of Political Ideologies from Five Democracies and GenomeWide Findings from Three Populations." Behavior Genetics 44(3): 282-94.

Havlicek, Jan, and S. Craig Roberts. 2009. "MHC-Correlated Mate Choice in Humans: A Review.” Psychoneuroendocrinology 34(4): 497-512.

Hawkley, Louise C., Mary H. Burleson, Gary G. Berntson, and John T. Cacioppo. 2003. "Loneliness in Everyday Life: Cardiovascular Activity, Psychosocial Context, and Health Behaviors." Journal of Personality and Social Psychology 85(1): 105-20.

Hawkley, Louise C., and John T. Cacioppo. 2003. "Loneliness and Pathways to Disease." Brain, Behavior and Immunity 17(Suppl. 1): S98-S105. 
Heining, Maike, Andrew W. Young, Glavkos Ioannou, Chris M. Andrew, Michael J. Brammer, Jeffrey A. Gray, and Mary L. Phillips. 2003. "Disgusting Smells Activate Human Anterior Insula and Ventral Striatum." Annals of the New York Academy of Sciences 1000: 380-84.

Herz, Rachel S., and Michael Inzlicht. 2002. "Sex Differences in Response to Physical and Social Factors Involved in $\mathrm{Hu}$ man Mate Selection: The Importance of Smell for Women." Evolution and Human Behavior 23(5): 359-64.

Inbar, Yoel, David A. Pizarro, and Paul Bloom. 2012. "Disgusting Smells Cause Decreased Liking of Gay Men." Emotion 12(1): 23-27.

Inbar, Yoel, David Pizarro, Ravi Iyer, and Jonathan Haidt. 2012. "Disgust Sensitivity, Political Conservatism, and Voting." Social Psychological and Personality Science 3(5): 537-44.

Jones, Doug, C. Loring Brace, William Jankowiak, Kevin N. Laland, Lisa E. Musselman, Judith H. Langlois, Lori A. Roggman, Daniel Pérusse, Barbara Schweder, and Donald Symons. 1995. "Sexual Selection, Physical Attractiveness, and Facial Neoteny-Cross-Cultural Evidence and Implications." Current Anthropology 36(5): 723-48.

Kalmijn, Matthijs. 1998. "Intermarriage and Homogamy: Causes, Patterns, Trends." Annual Review of Sociology 24: 395-421.

Keller, Andreas, Hanyi Zhuang, Qiuyi Chi, Leslie B. Vosshall, and Hiroaki Matsunami. 2007. "Genetic Variation in a Human Odorant Receptor Alters Odour Perception." Nature 449(7161): 468-72.

Klofstad, Casey A., Rose McDermott, and Peter K. Hatemi. 2012. "Do Bedroom Eyes Wear Political Glasses? The Role of Politics in Human Mate Attraction." Evolution and Human Behavior 33(2): 100-108.

Klofstad, Casey A., Rose I. McDermott, and Peter K. Hatemi. 2013. "The Dating Preferences of Liberals and Conservatives." Political Behavior 35(3): 519-38.

Kofoed, Emily. 2008. "The Role of Political Affiliations and Attraction in Romantic Relationships: Why Can't We All Just Get Along?" Advances in Communication Theory \& Research 2: $1-24$.

Martin, Nicholas G., Lindon J. Eaves, Andrew C. Heath, Rosemary Jardine, Lynn M. Feingold, and Hans J. Eysenck. 1986. "Transmission of Social Attitudes." Proceedings of the $\mathrm{Na}$ tional Academy of Sciences 83(12): 4364-68.

Martins, Yolanda, George Preti, Christina R. Crabtree, Tamar Runyan, Aldona A. Vainius, and Charles J. Wysocki. 2005. "Preference for Human Body Odors Is Influenced by Gender and Sexual Orientation.” Psychological Science 16(9): 694701 .

Mennella, Julie A., Coren P. Jagnow, and Gary K. Beauchamp. 2001. "Prenatal and Postnatal Flavor Learning by Human Infants." Pediatrics 107(6): E88. http:// pediatrics.aappublications.org/content/107/6/e88.long

Milinski, Manfred, Ilona Croy, Thomas Hummel, and Thomas Boehm. 2013. "Major Histocompatibility Complex Peptide Ligands as Olfactory Cues in Human Body Odour Assessment." Proceedings of the Royal Society B: Biological Sciences 280(1755).

Milinski, Manfred, and Claus Wedekind. 2001. "Evidence for MHC-Correlated Perfume Preferences in Humans." Behavioral Ecology 12(2): 140-49.
Miller, Geoffrey. 2011. The Mating Mind: How Sexual Choice Shaped the Evolution of Human Nature. New York: Anchor Books.

Miller, Geoffrey, Joshua M. Tybur, and Brent D. Jordan. 2007. "Ovulatory Cycle Effects on Tip Earnings by Lap Dancers: Economic Evidence for Human Estrus?" Evolution and $\mathrm{Hu}$ man Behavior 28(6): 375-81.

Navarrete, Carlos David, and Daniel M. T. Fessler. 2006. "Disease Avoidance and Ethnocentrism: The Effects of Disease Vulnerability and Disgust Sensitivity on Intergroup Attitudes." Evolution and Human Behavior 27(4): 270-82.

Nettle, Daniel, Karthik Panchanathan, Tage Shakti Rai, and Alan Page Fiske. 2011. "The Evolution of Giving, Sharing, and Lotteries." Current Anthropology 52(5): 747-56.

Neuberg, Steven L., Douglas T. Kenrick, and Mark Schaller. 2011. "Human Threat Management Systems: Self-Protection and Disease Avoidance." Neuroscience \& Biobehavioral Reviews 35(4): 1042-51.

Nowak, Martin A, Kristina Tarczy-Hornoch, and Jonathan M Austyn. 1992. "The Optimal Number of Major Histocompatibility Complex Molecules in an Individual." Proceedings of the National Academy of Sciences 89(22): 1089699.

Penn, Dustin, and Wayne K. Potts. 1998. "Chemical Signals and Parasite-Mediated Sexual Selection." Trends in Ecology and Evolution 13(10): 391-96.

Penn, Dustin J., and Wayne K. Potts. 1999. "The Evolution of Mating Preferences and Major Histocompatibility Complex Genes." The American Naturalist 153(2): 145-64.

Phillips, M. L., A. W. Young, C. Senior, M. Brammer, C. Andrew, A. J. Calder, E. T. Bullmore, D. I. Perrett, D. Rowland, S. C. Williams, J. A. Gray, and A. S. David. 1997. "A Specific Neural Substrate for Perceiving Facial Expressions of Disgust." Nature 389(6650): 495-98. http://www.nature.com/ nature/journal/v389/n6650/abs/389495a0.html

Posner, Samuel, Laura Baker, Andrew Heath, and Nicholas Martin. 1996. "Social Contact, Social Attitudes, and Twin Similarity.” Behavior Genetics 26(2): 123-33.

Radwan, Jacek, Aleksandra Biedrzycka, and Wiesław Babik. 2010. "Does Reduced MHC Diversity Decrease Viability of Vertebrate Populations?” Biological Conservation 143(3): 537-44.

Rantala, Markus, and Urszula Marcinkowska. 2011. "The Role of Sexual Imprinting and the Westermarck Effect in Mate Choice in Humans." Behavioral Ecology and Sociobiology 65(5): 859-73.

Rikowski, Anja, and Karl Grammer. 1999. "Human Body Odour, Symmetry and Attractiveness." Proceedings of the Royal Society of London, Series B: Biological Sciences 266(1422): 869-74

Schaal, Benoist, Luc Marlier, and Robert Soussignan. 2000. "Human Foetuses Learn Odours from Their Pregnant Mother's Diet." Chemical Senses 25(6): 729-37.

Singh, Devendra. 1993. "Adaptive Significance of Female Physical Attractiveness: Role of Waist-to-Hip Ratio." Journal of Personality and Social Psychology 65(2): 293-307.

Stoker, Laura, and M. Kent Jennings. 1995. "Life-Cycle Transitions and Political Participation: The Case of Marriage." American Political Science Review 89(2): 421-33. 
Stoker, Laura, and M. Kent Jennings. 2006. "Political Similarity and Influence between Husbands and Wives." In The Social Logic of Politics, ed. Alan Zuckerman. Philadelphia, PA: Temple University Press, 421-23.

Thornhill, Randy, and Steven W. Gangestad. 1999. "The Scent of Symmetry: A Human Sex Pheromone That Signals Fitness?" Evolution and Human Behavior 20(3): 175-201.

Thornhill, Randy, Steven W. Gangestad, Robert Miller, Glenn Scheyd, Julie K. McCollough, and Melissa Franklin. 2003. "Major Histocompatibility Complex Genes, Symmetry, and Body Scent Attractiveness in Men and Women." Behavioral Ecology 14(5): 668-78.

Townsend, John M., and Gary D. Levy. 1990. "Effects of Potential Partners' Physical Attractiveness and Socioeconomic Status on Sexuality and Partner Selection." Archives of Sexual Behavior 19(2): 149-64.

Watson, David, Eva C. Klohnen, Alex Casillas, Ericka Nus Simms, Jeffrey Haig, and Diane S. Berry. 2004. "Match Makers and Deal Breakers: Analyses of Assortative Mating in Newlywed Couples." Journal of Personality 72(5): 1029-68.

Wedekind, Claus, and Sandra Furi. 1997. "Body Odour Preferences in Men and Women: Do They Aim for Specific MHC Combinations or Simply Heterozygosity?" Proceedings of the Royal Society, Series B: Biological Sciences 264(1387): 1471-79.

Woelfing, Benno, Arne Traulsen, Manfred Milinski, and Thomas Boehm. 2009. "Does Intra-Individual Major His- tocompatibility Complex Diversity Keep a Golden Mean?” Philosophical Transactions of the Royal Society, Series B: Biological Sciences 364(1513): 117-28.

Zietsch, Brendan P., Karin J. Verweij, Andrew C. Heath, and Nicholas G. Martin. 2011. "Variation in Human Mate Choice: Simultaneously Investigating Heritability, Parental Influence, Sexual Imprinting, and Assortative Mating." The American Naturalist 177(5): 605-16.

Zuckerman, Alan S., Jennifer Fitzgerald, and Josip Dasovic. 2005. "Do Couples Support the Same Political Parties?" In The Social Logic of Politics, ed. Alan S. Zuckerman. Philadelphia, PA: Temple University Press, 75-94.

\section{Supporting Information}

Additional Supporting Information may be found in the online version of this article at the publisher's website:

Instructions for Target Subjects

Instructions for Evaluators

Cross-tabulations of sex and ideology

Models using jackknife standard errors

Mixed Models 